\title{
Insights on the environmental impacts associated with visible disturbance of ice-free ground in Antarctica
}

\author{
SHAUN T. BROOKS ${ }^{1}$ 1, PABLO TEJEDO² and TANYA A. O'NEILL ${ }^{3,4}$ \\ ${ }^{I}$ Institute for Marine and Antarctic Studies, University of Tasmania, Hobart, Tasmania, Australia \\ ${ }^{2}$ Departamento de Ecología, Universidad Autónoma de Madrid, Madrid, Spain \\ ${ }^{3}$ Environmental Research Institute, University of Waikato, Hamilton, New Zealand \\ ${ }^{4}$ School of Sciences, University of Waikato, Hamilton, New Zealand \\ stbrooks@utas.edu.au
}

\begin{abstract}
The small ice-free areas of Antarctica provide an essential habitat for most evident terrestrial biodiversity, as well as being disproportionately targeted by human activity. Visual detection of disturbance within these environments has become a useful tool for measuring areas affected by human impact, but questions remain as to what environmental consequences such disturbance actually has. To answer such questions, several factors must be considered, including the climate and biotic and abiotic characteristics. Although a body of research has established the consequences of disturbance at given locations, this paper was conceived in order to assess whether their findings could be generalized as a statement across the Antarctic continent. From a review of 31 studies within the Maritime Antarctic, Continental Antarctic and McMurdo Dry Valleys regions, we found that 83\% confirmed impacts in areas of visible disturbance. Disturbance was found to modify the physical environment, consequently reducing habitat suitability as well as directly damaging biota. Visible disturbance was also associated with hydrocarbon and heavy metal contamination and non-native species establishment, reflecting the pressures from human activity in these sites. The results add significance to existing footprint measurements based on visual analysis, should aid on-the-ground appreciation of probable impacts in sites of disturbance and benefit environmental assessment processes.
\end{abstract}

Received 27 June 2019, accepted 9 October 2019

Key words: contamination, footprint, habitat, non-native species, soil, wilderness

\section{Introduction}

The extent of the human disturbance footprint for the entire Antarctic continent has recently been calculated (Brooks et al. 2019). This and many similar footprint studies (e.g. Kennicutt II et al. 2010, O'Neill et al. 2013) have based their assessments of disturbance on visual detection through field, aerial or satellite observations. Visible disturbance to ice-free ground has an inherent impact on the wilderness and aesthetic values of Antarctica, protected through its designation as a natural reserve by the Protocol on Environmental Protection to the Antarctic Treaty (the Madrid Protocol) (Antarctic Treaty Secretariat 1991). However, can visible disturbance also generally be associated with further impacts on physical and ecological processes across the continent? This work examines the next sequential step to these footprint measurements, as we approach this question in two ways. The first is a review of the current understanding of the origins, processes and impacts of ground disturbance in Antarctica. The second is a quasi-meta-analysis, in which we assess whether the existing literature investigating impacts in sites of disturbance is sufficient to be generalized across the ice-free areas of Antarctica, divided into three major regions: the Maritime Antarctic, Continental Antarctic and the McMurdo Dry Valleys (see the 'Regionalization' section for a more detailed explanation). In addressing this question, we also deliver a mechanistic model of disturbance processes that lead to impacts (Fig. 1), which can be applied across Antarctica.

\section{General characteristics of Antarctic soils}

In many parts of Antarctica, where polar desert soil moisture regimes occur (e.g. Continental Antarctica and McMurdo Dry Valleys), physical weathering processes dominate and chemical weathering is restricted due to cold temperatures and a lack of liquid moisture (Convey et al. 2014). In these dry environments, soils typically have a desert pavement surface that is composed of gravels and stones. Desert pavement forms as finer 


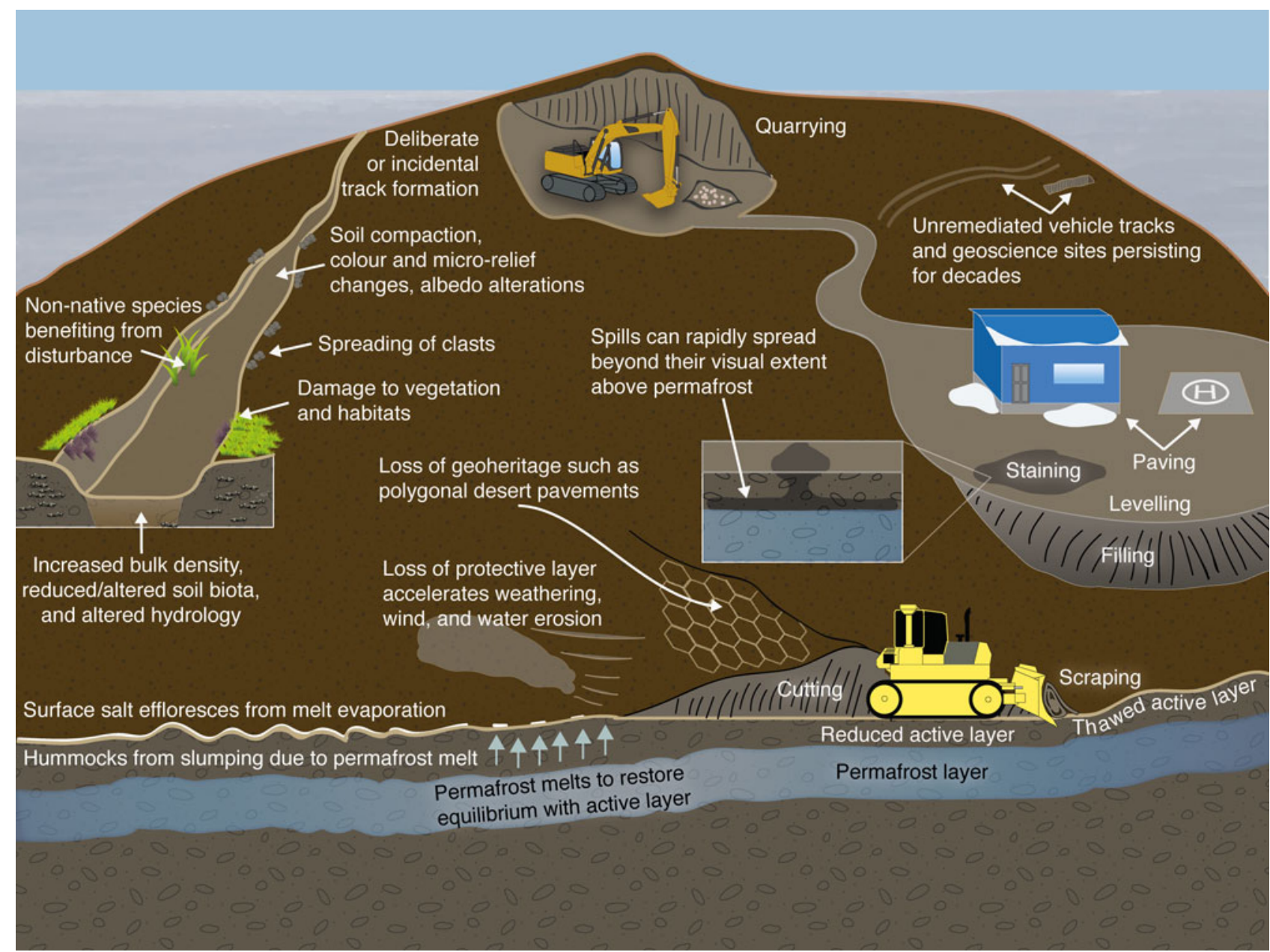

Fig. 1. Processes, impacts and visual cues associated with disturbance. This model illustrates the main processes and impacts of disturbance from human activity typically found within ice-free areas of Antarctica. Many impacts associated with track formation (top left) are also common at sites of levelling and paving (mid-right). Although infrastructure establishment to support research stations has been the biggest source of ground disturbance, pressure from walking tracks will increase as the tourism industry grows.

materials are eroded, primarily by wind, until a protective surface layer of coarser material remains. Mature, undisturbed Antarctic desert pavements are typically characterized by a closely packed layer of gravel, cobble and boulder-sized material, which can be ventifacted, pitted and coated with desert varnish, depending on age (Balks \& O'Neill 2016). Beneath the desert pavement, soil materials are generally loose and unconsolidated. The depth to which soils thaw each summer is referred to as the active layer. Beneath the active layer is permafrost, defined as having a temperature of $<0^{\circ} \mathrm{C}$ for at least two consecutive years (Grosse et al. 2011, Soil Survey Staff 2014). The water content of permafrost in Antarctica can vary from being ice-cemented to dry frozen (Campbell et al. 1998). For much of the year, Antarctic soils are at temperatures $<0^{\circ} \mathrm{C}$; however, over the summer months (December-January), when sunlight is present for up to 24 hours per day, the soils are warmed at the surface, providing some opportunity for liquid moisture and biological activity (Convey et al. 2018). This effect increases with decreasing latitude, being most evident within the Maritime Antarctic and a few coastal locations, where warmer temperatures and moisture availability enable sufficient biological activity to create some organic soils (Convey et al. 2014 and references therein). These characteristics of Antarctic soils, combined with the general absence of higher vegetation (vascular plant species) and prevailing low temperatures, result in a general vulnerability to rapid and/or long-lasting visible ground disturbance.

\section{Significance of ice-free ground disturbance}

The Antarctic continent has a land area that is larger than Europe mainly covered by ice up to $4 \mathrm{~km}$ thick. Despite the abundance of ice-covered environments, the majority 


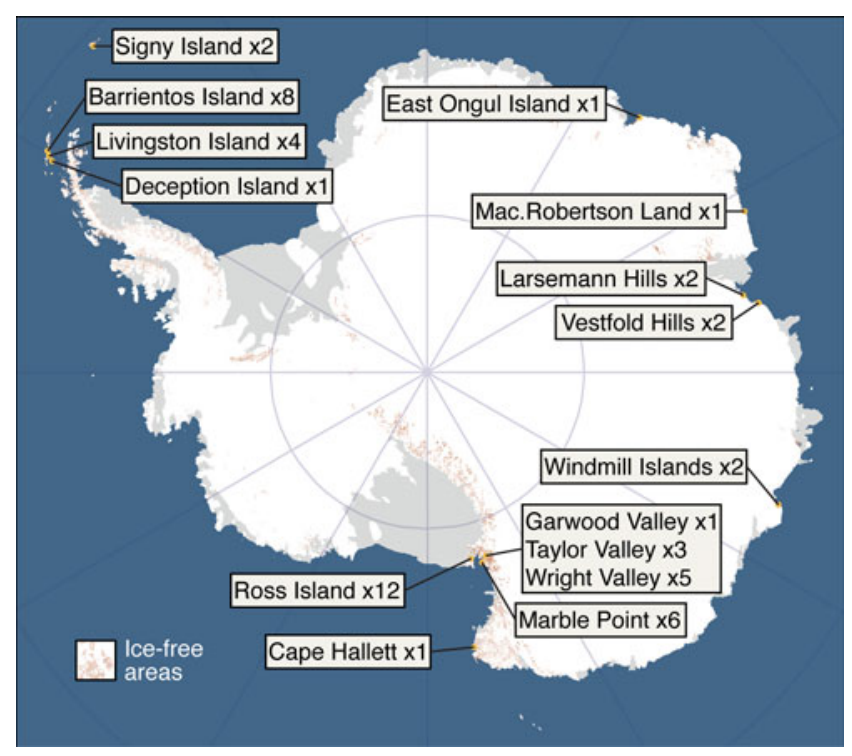

Fig. 2. Locations involved within this review. The locations involved within this review were distributed across the three broad regions of Antarctica, with concentrations in areas of accessibility, scientific interest and higher levels of footprint (see Brooks et al. 2019). This figure presents the locations of studies that provided specific sites. Note: several studies included sites within multiple locations.

of terrestrial biodiversity is found within the small, ice-free areas that make up $<0.5 \%$ of the continent (Convey et al. 2014, Brooks et al. 2019), centred around the Transantarctic Mountains, Mac. Robertson Land, Dronning Maud Land and the coast and islands of the Antarctic Peninsula (Bockheim 2015) (Fig. 2). These scattered 'oases' of land provide the essential habitat for Antarctica's bryophytes, lichens, microbiota, nesting seabirds, most penguin species' rookeries and two vascular plant species (restricted to the Maritime Antarctic, north of $70^{\circ} \mathrm{S}$; Bergstrom et al. 2006; Convey et al. 2011, 2014). Representation of this biodiversity is not homogenous, with 16 unique areas classified by the Antarctic Conservation Biogeographic Regions (ACBRs; Terauds \& Lee 2016). These areas also provide the only locations to observe Antarctic geomorphology, including rare minerals, desert pavements and finite fossil sites (Kiernan \& McConnell 2001a, O'Neill 2017). Despite the outstanding scientific, environmental and ecosystem values present within these small areas, they are disproportionately impacted by human activity. The majority of all buildings on the continent $(76 \%)$ are focused within just $0.06 \%$ of Antarctica, the important ice-free areas adjacent to the coast (Convey et al. 2014, Brooks et al. 2019). Accompanying these buildings are over 5.2 million $\mathrm{m}^{2}$ of visibly disturbed ice-free ground (detectable within satellite imagery), primarily concentrated in two centres of activity (the Northwest
Antarctic Peninsula and South Victoria Land), but also spread out, with more than half of all large coastal ice-free areas having impacts present (Brooks et al. 2019).

\section{Sources of disturbance}

Most disturbance to ice-free ground in Antarctica is in close proximity to research stations or as a result of research activities (O'Neill et al. 2015a, Brooks et al. 2019). Many of these sites have a long-term human presence, are the only permanent infrastructure on land and the human activity from their combined populations and time spent ashore far exceeds tourism (despite peaking at $<5000$ people) (Jabour 2009, www.comnap. aq/Information/SiteAssets/SitePages/Home/Antarctic_ Facilities_List_27July16.pdf). The disturbance footprint created by stations is a product of planned activities (permitted through environmental impact assessments), cumulative impacts and historic practices, with most disturbance having been established before the introduction of the environmental framework established by the Madrid Protocol (Brooks et al. 2018a, 2018b). Planned earthwork activities to establish or expand a station and its infrastructure (including roads, wharfs, airfields and fuel handling) have undoubtedly been the largest single source of ground disturbance (see Klein et al. 2004, O'Neill et al. 2015a). Scientific investigations have resulted in impacts of a similar severity, but are far less common (e.g. Kiernan \& McConnell 2001a). Vehicles and to a lesser extent pedestrian activity (including substantial tourism landings) have then contributed to forming and cumulatively expanding the distribution of disturbed sites across the continent (O'Neill et al. 2015b).

\section{Processes creating disturbance}

The broad processes that have led to visible disturbance of ice-free areas involve adding, compacting or removing surface substrate. Adding 'fill' to areas is a common practice deliberately used to establish building foundations and road bases (Fig. 1) and has occurred in all but the most rudimentary of stations. Surrounding these areas, and at sites of scientific or tourism interest (except rocky outcrops), incidental compression and compaction of substrates occur from vehicle and pedestrian activity (including camping, helicopter landings, hut access and recreation; Tejedo et al. 2005, 2009). Pedestrian activity causes further disturbance through incidental spreading of clasts, degradation of surface vegetation and ecosystems and human-induced erosion (Burgess et al. 1992, Campbell et al. 1993, Pertierra et al. 2013, O'Neill et al. 2015a, 2015b). Secondary substrate compression also occurs around station facilities as a result of temporary vehicular and 
pedestrian access during construction activities (Brooks 2014). These processes are further intensified by most human activity in Antarctica occurring during summer, when peak active-layer melt and minimal snow cover increase the susceptibility of substrates to disturbance (Hodgson et al. 2010, O'Neill et al. 2015a, Convey et al. 2018). The persistence of the effects from compression depend on substrate vulnerability (O'Neill et al. 2015a and references therein), but have been known to result in long-lasting visual impacts as rapidly as only one pedestrian pass (Campbell et al. 1993, Hodgson et al. 2010, O'Neill 2013). Severe removal of substrates (soil/gravel and rock outcrops) is typically deliberate, in the form of quarrying, excavation and surface scraping for fill by heavy machinery (Kiernan \& McConnell 2001a, Klein et al. 2004, Braun et al. 2012, 2014) (Fig. 1).

\section{Visibility of disturbance}

As a consequence of these processes and the typically vulnerable physical properties of Antarctic soils (O'Neill et al. 2015a), even low levels of human disturbance to ice-free ground can rapidly become visible. Due to this, visual cues are commonly used to establish and detect the severity of human impacts (e.g. Campbell et al. 1993, Kiernan \& McConnell 2001a, Goldsworthy et al. 2003). Campbell et al. (1993) established a human impact assessment tool based on visual criteria, including surface colour changes, upturning of clasts, surface uniformity, presence of foreign objects and vegetation disturbance. Although based on the Ross Sea region, these cues have also been adapted to the Vestfold Hills (Kiernan \& McConnell 2001b) and are generally applicable to the non-vegetated environments of the Maritime Antarctic. Because of this ease of detection, mapping of visibly disturbed ground has become a useful proxy for spatially quantifying sites of human impacts in the field and through remote sensing (e.g. O'Neill et al. 2013, Bollard-Breen et al. 2014, Brooks et al. 2019).

\section{Impacts associated with disturbance}

Disturbance to ice-free substrates throughout Antarctica generally has pronounced impacts due to the typically vulnerable physical properties of the soils, low temperatures, slow recovery rates, simple ecosystems and limited previous human activity (O'Neill et al. 2015a and references therein). The consequences of physical disturbance include changes to soil dynamics (moisture balance, hydrology, infiltration capacity, resistance to compression, bulk density and $\mathrm{CO}_{2}$ fluxes), loss of the protective desert pavement surface layer (potentially resulting in landscape instability, accelerated weathering, wind and water erosion, loss of geoheritage and increased ultraviolet (UV) penetration) and melt of permafrost (O'Neill et al. 2015a and references therein) (Fig. 1). As permafrost can have an ice content $>80 \%$ by volume, the loss of this mass from melt (up to $2501 \mathrm{~m}^{-3}$ ) due to removal of the insulating active layer can result in significant landscape slumping (Campbell et al. 1994). When permafrost melts and water evaporates, concentrated salt previously trapped in the ice-cemented layer effloresces at the surface, which can appear similar to snow (Campbell et al. 1994, O'Neill et al. 2015a). Such changes to abiotic soil conditions can be considered as environmental impacts significant in themselves and they can have flow-on effects (e.g. salt effloresces reduce surface albedo), but they can also interfere with ecosystem processes, including reducing habitat suitability (O'Neill et al. 2015a and references therein).

Ground disturbance in Antarctica can impact biota both directly and as a consequence of changes to their physical environment. Although edaphic species have survived for millennia in Antarctic conditions, their simplified ecosystems and adaptation to an adverse climate have generally resulted in their being vulnerable to environmental change (Convey 2010 and references therein). Loss of landscape stability, soil compression, moisture changes and a greater UV exposure following disturbance will generally reduce the habitat suitability for edaphic fauna (Wall \& Virginia 1999). These may be accompanied by other environmental changes, such as soil chemistry (e.g. salinity, $\mathrm{pH}$, hydrocarbons and heavy metals; Tin et al. 2009 and references therein) and temperature (albedo; Balks et al. 2002). Aboveground physical consequences to biota also occur, with cryptogamic communities being easily damaged by trampling (Pertierra et al. 2013), subsequently reducing the habitat and protective cover they provide (Tejedo et al. 2016) and further contributing to long-lasting visible disturbance (e.g. Pertierra et al. 2017). Physical modification of geomorphology can also have indirect impacts, with examples including Adélie penguins failing to reoccupy abandoned sites due to the past levelling of nesting mounds (Wilson et al. 1990). Disturbance has also been found to benefit the establishment of non-native species, especially ruderals, including the grass Poa annua (Molina-Montenegro et al. 2014). Here, disturbance and climate change (projected to also benefit non-native species; Duffy et al. 2017) may act synergistically, especially within the at-risk Maritime Antarctic (Chown et al. 2012), to increase landscape susceptibility to invasion.

\section{Factors influencing persistence of disturbance}

Although the spatial extent and severity of disturbance are dependent on the type of activity, local environmental factors and soil substrate characteristics influence the 
intensity and persistence of the visual impact (Brooks et al. 2018a). For soil and gravel environments, where $78 \%$ of stations in ice-free areas are found (Brooks et al. 2019), numerous factors affect recovery time. Disturbance to active environments (where wind, flowing water, waves or freeze-thaw processes are ongoing) can appear rapidly, but also disappear relatively quickly (e.g. footprints in sand dunes; O'Neill et al. 2015a and references therein). Beyond active environments, soil resilience in Antarctica is influenced by substrate type (including hardness, age and grain size), stage of weathering and moisture regime ( $\mathrm{O}^{\prime} \mathrm{Neill}$ et al. 2015a). Older, drier, weathered sites are typically the most vulnerable, with vehicle tracks and hydrocarbon staining remaining clearly visible after 40 years $\left(\mathrm{O}^{\prime} \mathrm{Neill}\right.$ et al. 2015a) and full natural recovery possibly taking hundreds of years, if it occurs at all (Kiernan \& McConnell 2001b, Kennicutt II et al. 2010). Rock outcrop areas are inherently more resilient to human activity, apart from discolouration and damage to resident flora/lichens; however, quarrying, blasting or drilling in these environments results in irrevocable damage. Although remediation can accelerate visual recovery in certain environments (O'Neill et al. 2012, 2013), long-term changes to underlying permafrost persist (Campbell et al. 1994) and uncertainty remains regarding its effectiveness for reducing subsequent biological impacts (O'Neill et al. 2015a).

\section{Materials and methods}

\section{Research approach}

The aim of this paper was to establish whether the existing field of research was sufficient to infer that impacts to further values (beyond wilderness and aesthetics) can generally be expected from visible disturbance to ice-free areas across Antarctica. To assess this, our approach was based on a comprehensive review of research attempting to detect anthropogenic changes to the abiotic and biotic natural environment within sites of visibly detectable, persistent, disturbed ice-free ground. The possibility of conducting a meta-analysis or systematic review was considered, but this was not possible due to the insufficient replication of similar studies across the various species, ACBRs (Terauds \& Lee 2016) or environmental domains (Morgan et al. 2005) present in Antarctica.

\section{Regionalization}

From the initial review, it became clear that disturbance to soil terrestrial environments in certain parts of Antarctica resulted in different impacts compared to others (e.g. the Maritime Antarctic compared to the McMurdo Dry
Valleys). The consequences of disturbance were found to be linked to environmental characteristics, such as soil moisture, so different impacts were expected to be detected across Antarctica. Similarly, the research effort has focused on the impacts specifically arising from these environmental characteristics and has been concentrated within locations of accessibility, historic disturbance and scientific interest. Based on these environmental and research effort divisions, the regions determined to be relevant to this study were the Maritime Antarctic (the Antarctic Peninsula and its archipelagos) and Continental Antarctic (consistent with the traditional biogeographical zones; e.g. Huiskes et al. 2006) and the McMurdo Dry Valleys (divided from the Continental Antarctic due to their unique characteristics). These broad regions captured the majority of human activity in ice-free areas and provided a sufficient body of research to investigate. The main ice-free areas not captured within the continental region were inland sites, predominantly Dronning Maud Land, Marie Byrd Land and the Transantarctic Mountains (Fig. 2), due to their limited human activity, human impacts research or stations (in the latter two).

\section{Data used}

Due of the limited quantity of research investigating disturbance-related impacts in Antarctica, all findings of detected changes were considered. These ranged from reduced penguin nesting to bacterial diversity, and from soil moisture content through to changes in permafrost. In cases where multiple impacts were assessed by a single study, these were divided into separate results $(n=15)$. In total, there were 46 applicable results (from 31 studies), with many of these based on numerous study locations. The results from Molina-Montenegro et al. (2014), for example, were based on an investigation of 25 sites. To disseminate the gathered data, the impacts were broadly categorized as biotic and abiotic, followed by subcategories including fauna types, vegetation types, non-native species, contamination and soil properties. Each study was then reviewed for whether an impact was detected, whether quantitative analyses were performed and whether it was based on an experiment or observations. The results reported here indicate the type and number of studies investigated where changes to the environment and biota were studied. Although the changes are referred to here as 'impacts', some of the actual effects on biota or environment types may be considered small or to have resulted in negligible consequences to broader ecosystems. Alternatively, a portion of the disturbance investigated may have resulted in long-term, irreversible changes to parts of the Antarctic landscape. For example, within many Antarctic station sites, particularly those 
Table I. Summary of abiotic impacts within the literature assessed. References are provided in Table S1.

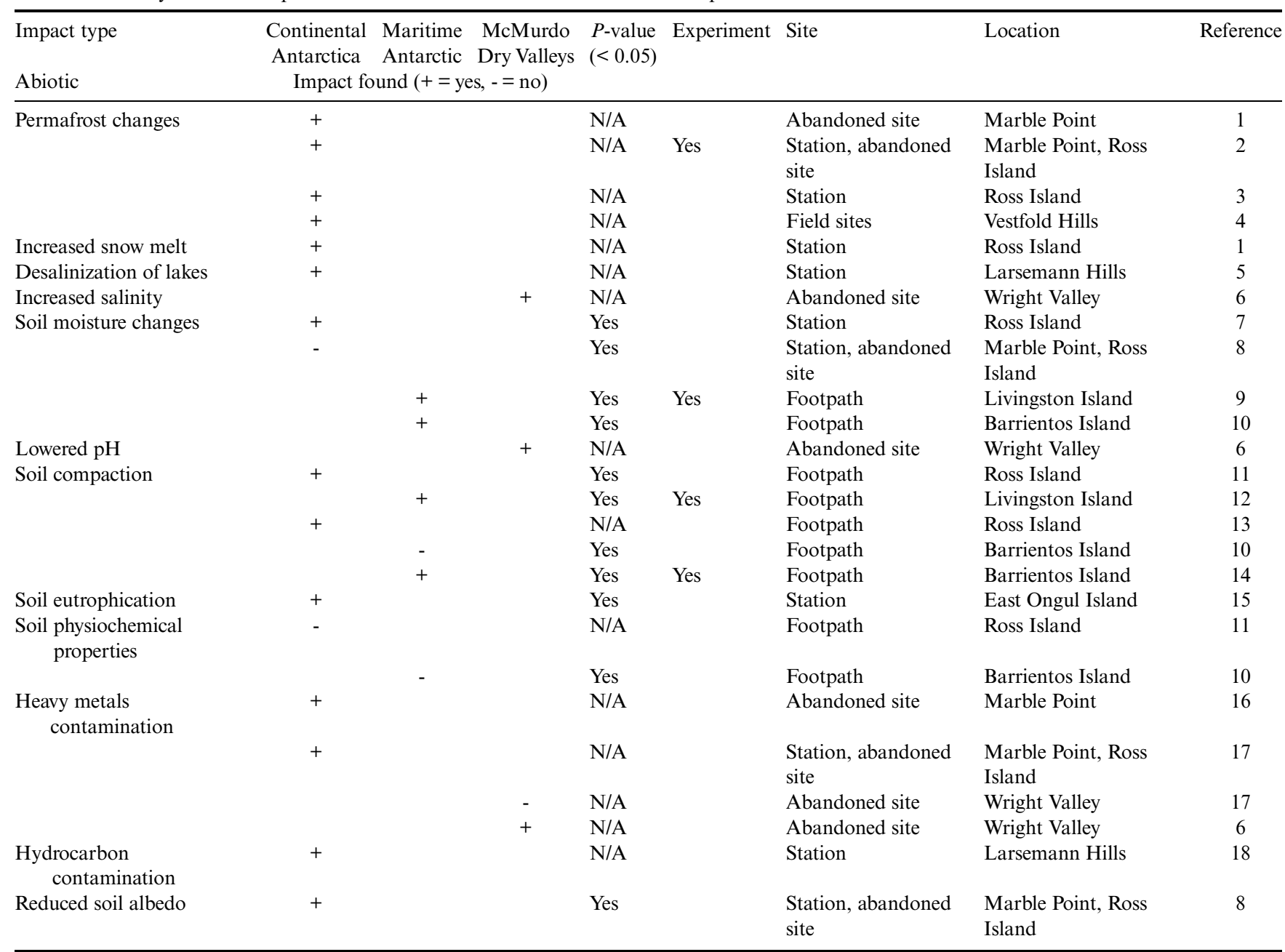

built before the Madrid Protocol, disturbance of a high severity is common (O'Neill et al. 2015a; O'Neill 2017).

\section{Results}

Of the 46 results reviewed, $83 \%(n=38)$ found further impacts in sites of disturbance (Tables I \& II). Half of all studies involved used statistically robust sampling techniques, whereas the remainder reported on measurements and observations. From the half that used statistical analyses, $74 \%$ found that impacts were present $(P<0.05)$. In total, nine of the reports were based on experimental disturbance of a site to enable detection of impacts under controlled conditions (Tables I \& II). Twenty-two of the reports were from Continental Antarctica (eight locations), 17 were from the Maritime Antarctic (four locations) and seven were from the McMurdo Dry Valleys region (three locations) (Fig. 2).

The majority of all reports from Continental Antarctica investigated abiotic impacts, whereas the majority of
Maritime Antarctic reports studied biological values. The seven reports from the McMurdo Dry Valleys were split between abiotic and biotic impacts, reflecting both the focus and limited quantity of applicable studies there. In total, $81 \%$ of abiotic studies reported an impact $(n=22)$ and $84 \%$ of biotic studies reported an impact $(n=16)$ (Tables I and II). Changes to soil properties were the most common form of impact assessed $(n=18)$, followed by impacts to fauna $(n=11)$, contamination $(n=6)$, degradation of flora $(n=4)$ and non-native species $(n=4)$. The majority of studies investigated sites of current or former stations $(n=24)$, followed by footpaths/walking tracks $(n=18)$ and scientific field sites $(n=3)$.

\section{Discussion}

The majority of studies involved in this review identified biotic and abiotic environmental impacts (beyond wilderness and aesthetic values) within sites of lasting visible disturbance. Although the consequences of 
Table II. Summary of biotic impacts within the literature assessed. References are provided in Table S1.

\begin{tabular}{|c|c|c|c|c|c|c|c|c|}
\hline Impact type & $\begin{array}{l}\text { Continental } \\
\text { Antarctica } \\
\text { Impact fo }\end{array}$ & $\begin{array}{l}\text { Maritime } \\
\text { Antarctic } \\
\text { und }(+=y\end{array}$ & $\begin{array}{l}\text { McMurdo } \\
\text { Dry Valleys } \\
\text { es, - = no) }\end{array}$ & $\begin{array}{l}P \text {-value } \\
(<0.05)\end{array}$ & Experiment & Site & Location & Reference \\
\hline \multirow[t]{2}{*}{ Collembola } & & + & & Yes & Yes & Footpath & Livingston Island & 19 \\
\hline & & + & & N/A & & Footpath & Barrientos Island & 20 \\
\hline \multirow[t]{2}{*}{ Nematodes } & & & + & Yes & & Footpath & Taylor Valley & 21 \\
\hline & & & + & Yes & Yes & Field sites & $\begin{array}{l}\text { Garwood, Taylor and } \\
\text { Wright valleys }\end{array}$ & 22 \\
\hline $\begin{array}{l}\text { Soil biota (nematodes, } \\
\text { rotifers and tardigrades) }\end{array}$ & & & + & Yes & & Footpath & Taylor Valley & 21 \\
\hline \multirow[t]{4}{*}{ Soil bacteria } & & - & & Yes & & Station & Signy Island & 23 \\
\hline & & + & & N/A & & Station & Signy Island & 23 \\
\hline & & + & & Yes & & Footpath & Barrientos Island & 10 \\
\hline & - & & & Yes & & Station & Windmill Islands & 24 \\
\hline & & + & & Yes & & Footpath & Barrientos Island & 20 \\
\hline \multirow[t]{2}{*}{ Moss/lichen } & & + & & Yes & Yes & Footpath & Livingston Island & 9 \\
\hline & + & & & N/A & & Station & Ross Island & 29 \\
\hline NNS - Collembola & & + & & N/A & & Footpath & Barrientos Island & 20 \\
\hline NNS - fungi & + & & & N/A & & Station, abandoned site & Windmill Islands & 30 \\
\hline \multirow[t]{2}{*}{ NNS - grass (Poa аппиа) } & & + & & Yes & & Station & Various & 31 \\
\hline & & + & & Yes & Yes & Station & Various & 31 \\
\hline
\end{tabular}

NNS = non-native species.

disturbance vary by region across the continent, as do the focuses of the studies, the majority of cases reviewed here suggest, in most circumstances, that with similar environmental conditions further impacts are probable. While this was the hypothesized result, conducting a continent-wide review has helped to establish the likelihood that such findings could be generalized as a statement across the whole Antarctic continent. Although the statistical rigour of a meta-analysis was not possible, Tables I \& II have provided a summary of the current knowledge regarding the ecological and physiological consequences underlying visibly disturbed ground in Antarctica.

\section{How impacts occurred}

There were three broad, interrelated pathways identified within this review where ground disturbance led to further impacts. For biotic impacts, ground disturbance typically led to increased soil bulk density (compaction) and altered moisture availability, consequently reducing the habitat suitability for flora and edaphic fauna. This disturbance also caused direct mechanical damage of biota. This alteration of soil habitats may also benefit non-native species establishment (as with natural perturbation; Olech 1996, Olech \& Chwedorzewska 2011, Molina-Montenegro et al. 2014). For abiotic impacts, disturbance modified the natural protective desert pavement surface layer (which may also damage unique geomorphological values), typically disturbing or removing the active layer, forcing the disturbed permafrost to re-establish an equilibrium with the surface. In many cases, melt out of permafrost led to surface slumping and surface salt efflorescence, leading to further negative biological effects. The third pathway is the virtually unavoidable concomitant pressures of human activity associated with disturbed ground. These include contamination with hydrocarbons, heavy metals, eutrophication and non-native species introductions, all of which are inherently more common in locations of long-term human presence and activity (e.g. Bargagli 2008, Cowan et al. 2011, Klein et al. 2012, Houghton et al. 2014, Brooks et al. 2018b, Newman et al. 2018).

The consequences of disturbance can also extend out beyond visibly impacted areas. As there are very few paved roads within Antarctica, the utilization of gravel roads can cause erosion, run-off and the generation of dust (e.g. Campbell et al. 1994). Although liquid water is relatively scarce in Antarctica, summer melt is known to channel in roads, leading to sedimentation and altered salinity within Antarctic lakes (Burgess et al. 1992). This limited moisture availability can also increase the concentration of contaminants within run-off due to the lack of regular flushing (Sheppard et al. 1997, Claridge et al. 1999). Within moister environments, where 
ice-cemented permafrost occurs, contaminants such as fuels can also spread rapidly underneath the surface beyond the visible spill point by migrating laterally on top of the frozen layer (Claridge et al. 1999, Campbell et al. 2003) (Fig. 1). Although dust generated from disturbed ground and deposition onto snow and ice is known to increase meltwater in Antarctica (Campbell et al. 1994), the edge effects and dust deposition from heavily disturbed ground (such as roads and staging areas) on surrounding flora and edaphic fauna have been observed, but such observations are currently unpublished. Within the Arctic, examples of gravel road edge effects include higher $\mathrm{pH}$, reduced nutrients, increased bulk density, lower moisture content, altered snow cover, deeper permafrost thaw, reduced species richness and between two to five times less vegetation biomass at $2 \mathrm{~m}$ from the road compared to $100 \mathrm{~m}$ distance (Auerbach et al. 1997). While acknowledging substantial environmental differences from the Arctic, some of these effects must occur in Antarctica, and so these warrant further study where new roads are proposed in ice-free areas.

\section{Regional differences in impacts associated with visible ground disturbance}

The locations of the studies involved were typically accessible sites frequented by human activity, sites of significant past human impacts including contamination or sites of scientific interest (Fig. 2). For Continental Antarctica, nine of the 22 reports were from sites surrounding McMurdo Station and Scott Base on Ross Island, reflecting the relative accessibility, concentration of research activities and long-term human presence and subsequent landscape degradation in the area. A further six studies were based on Marble Point, typically the access point to and from the McMurdo Dry Valleys and Northern Victoria Land (across McMurdo Sound from Ross Island), which was greatly impacted by an abandoned attempt to build a $3 \mathrm{~km}$ runway there in the late 1950s (Broadbent 2009). Research within the McMurdo Dry Valleys was split between the former Vanda Station site and the formation of walking tracks from science and tourism. The focus of these studies was on abiotic conditions (which ultimately drive biology) and probably reflects both the long-term persistence of impacts and typically sporadic biota within these cold desert environments.

Studies from the Maritime Antarctic, however, were focused on the more pronounced biota in this region, concentrating on islands, non-native species and walking track formation. This biotic focus is consistent with the increased biological activity that occurs there, supported by the wetter moisture regime, more mature soils and warmer temperatures. The emphasis on tracks within ice-free areas may be attributed to the Maritime Antarctic representing the most diverse terrestrial Antarctic ecosystems (Convey 2010, Tejedo et al. 2016), more walking-based scientific activity (Pertierra et al. 2017) and relatively frequent pedestrian activity introduced by ship-based tourism. By extrapolating these results to station environments within the region, heavily disturbed sites with intense human activity are expected to have similar or more pronounced impacts compared with those found from walking tracks. The northern Antarctic Peninsula and South Shetland Islands are also consistently recognized as the most susceptible parts of the continent to non-native species invasion due to ease of accessibility and comparatively milder climatic conditions (Chown et al. 2012), warranting the research effort. As shifts in the viability of biota due to climate change are already being detected at Maritime Antarctic sites (Amesbury et al. 2017) and on the continent (Robinson et al. 2018), the impacts associated with disturbance will probably have a changing and possibly compounding effect with projected warming (e.g. Duffy et al. 2017, Lee et al. 2017).

\section{Research gaps}

Finally, we must highlight that the process of this review has helped identify gaps in the current field of knowledge. This study focused on impacts detected within the immediate proximity of visible disturbance. Many of these impacts are known to extend out beyond the obviously disturbed area (e.g. dust settling on vegetation), but there is currently limited research available from Antarctica to quantify these effects. Investigation into the effectiveness of remediation of disturbed sites in relation to the impacts reviewed here (beyond contamination, wilderness and aesthetic values) warrants further research. Furthermore, this study has highlighted significant regional differences in subsequent impacts from disturbance, and as a consequence we recommend adapting the criteria used in visual site assessment tools (e.g. Campbell et al. 1993, Kiernan \& McConnell 2001b, O'Neill et al. 2012) to allow their application to the vegetated areas typical of the Maritime Antarctic. Utilization of these modified visual site assessment tools in these areas should enable practical improvements in environmental impact assessments and disturbance mitigation measures for use within Antarctica.

\section{Conclusion}

Compared with all other continents, the area of Antarctica observably modified by human activities is very small. This is consistent with its designation as a natural reserve. The current footprint of disturbance, however, takes on more significance considering its focus within the most biologically significant parts of the continent, concentrated by short influxes of human activity during 
the summer when substrates are most vulnerable. Many of the impacts reported here may not be considered severe, but they all affect environmental and ecosystem processes protected by the Madrid Protocol.

Our results suggest visually observable disturbed ground within the ice-free environment across Antarctica is, in most cases, an indicator of further impacts to biotic and abiotic processes. This adds a layer of significance to the 5.2 million $\mathrm{m}^{2}$ of disturbed ground measured from satellite imagery, as well as adding value to all of the existing studies that have used visual methods to assess local-scale human impacts. These results and the summary of the literature should be of value to studies of disturbance in ice-free areas (from science and tourism activities), as well as providing a tool for observers for rapid assessment of potential environmental impacts seen during Antarctic Treaty station inspections. Similarly, this collation of data across the range of possible impacts associated with ground disturbance should help environmental management teams determine the accuracy of the probable impacts of proposed activities estimated within environmental impact assessments.

\section{Acknowledgements}

We thank D.M. Bergstrom, P. Convey and an anonymous reviewer for comments on an earlier version of this manuscript. This project was supported by an Antarctic Science Bursary, an IMAS Student Conference and Research Travel Grant and a Student Research Support Grant. STB is supported by an Australian Government Research Training Program Scholarship.

\section{Author contributions}

STB initiated the research and prepared a first draft of the manuscript and figures. All authors contributed to conceptual development, research, further drafting and revisions of the manuscript.

\section{Details of data deposit}

All data used within our analyses were extracted from publicly available published articles listed in Table S1.

\section{Supplementary material}

One table will be found at https://doi.org/10.1017/ S0954102019000440.

\section{References}

Amesbury, M.J., Roland, T.P., Royles, J., Hodgson, D.A., Convey, P., Griffiths, H. \& Charman, D.J. 2017. Widespread biological response to rapid warming on the Antarctic Peninsula. Current Biology, 27, 1616-1622.e1612.
Antarctic Treaty Secretariat. 1991. Protocol on Environmental Protection to the Antarctic Treaty. Buenos Aires: Antarctic Treaty Secretariat.

Auerbach, N.A., Walker, M.D. \& Walker, D.A. 1997. Effects of roadside disturbance on substrate and vegetation properties in arctic tundra. Ecological Applications, 7, 218-235.

Balks, M.R. \& O'Neill, T.A. 2016. Soil and permafrost in the Ross Sea region of Antarctica: stable or dynamic? Cuadernos de Investigación Geográfica, 42, 10.18172/cig.2923.

Balks, M.R., Paetzold, R.F., Kimble, J.M., Aislabie, J. \& CAmpbell, I.B. 2002. Effects of hydrocarbon spills on the temperature and moisture regimes of Cryosols in the Ross Sea region. Antarctic Science, 14, 319-326.

BARGaGli, R. 2008. Environmental contamination in Antarctic ecosystems. Science of the Total Environment, 400, 212-226.

Bergstrom, D.M., Hodgson, D.A. \& Convey, P. 2006. The physical setting of the Antarctic. In Bergstrom, D.M., Convey, P. \& Huiskes, A.H.L. eds. Trends in Antarctic terrestrial and limnetic ecosystems: Antarctica as a global indicator. Dordrecht: Springer, 15-33. BockheIm, J.G. 2015. The soils of Antarctica. Berlin: Springer.

Bollard-Breen, B., Brooks, J.D., Jones, M.R.L., Robertson, J., Betschart, S., Kung, O., et al. 2014. Application of an unmanned aerial vehicle in spatial mapping of terrestrial biology and human disturbance in the McMurdo Dry Valleys, East Antarctica. Polar Biology, 38, 573-578.

Braun, C., Mustafa, O., Nordt, A., Pfeiffer, S. \& Peter, H.-U. 2012. Environmental monitoring and management proposals for the Fildes Region, King George Island, Antarctica. Polar Research, 31, 18206.

Braun, C., Hertel, F., Mustafa, O., Nordt, A., Pfeiffer, S. \& Peter, H.-U. 2014. Environmental assessment and management challenges of the Fildes Peninsula region. In Tin, T., Liggett, D., Maher, P.T. \& Lamers, M., eds. Antarctic futures. Berlin: Springer, 169-191.

Broadbent, N.D. 2009. From ballooning in the Arctic to 10,000 foot runways in Antarctica: lessons from historic archaeology. In Krupnik, I., Lang, M.A. \& Miller, S.E., eds. Smithsonian at the Poles: contributions to International Polar Year Science. Washington, DC: Smithsonian Institution, 49-60.

BRooKs, S.T. 2014. Developing a standardised approach to measuring the environmental footprint of Antarctic research stations. Journal of Environmental Assessment Policy and Management, 16, 1450037.

Brooks, S.T., Jabour, J. \& Bergstrom, D.M. 2018a. What is 'footprint' in Antarctica: proposing a set of definitions. Antarctic Science, 30, 227-235.

Brooks, S.T., Jabour, J., Sharman, A.J. \& Bergstrom, D.M. 2018b. An analysis of environmental incidents for a national Antarctic program. Journal of Environmental Management, 212, 340-348.

Brooks, S.T., JABOUR, J., van den HofF, J. \& Bergstrom, D.M. 2019. Our footprint on Antarctica competes with nature for rare ice-free land. Nature Sustainability, 2, 185-190.

Burgess, J., Spate, A. \& Norman, F. 1992. Environmental impacts of station development in the Larsemann Hills, Princess Elizabeth Land, Antarctica. Journal of Environmental Management, 36, 287-299.

Campbell, I.B., Balks, M.R. \& Claridge, G.G.C. 1993. A simple visual technique for estimating the impact of fieldwork on the terrestrial environment in ice-free areas of Antarctica. Polar Record, 29, 321-328.

Campbell, I.B., Claridge, G.G.C. \& Balks, M.R. 1994. The effect of human activities on moisture content of soils and underlying permafrost from the McMurdo Sound region, Antarctica. Antarctic Science, 6, 307-314.

Campbell, I.B., Sheppard, D.S. \& Claridge, G.G.C. 2003. Relationships and significance of contaminants in soils of the Transantarctic Mountains. Polar Record, 39, 301-308. 
Campbell, I., Claridge, G., Campbell, D. \& Balks, M. 1998. Permafrost properties in the McMurdo Sound-Dry Valley region of Antarctica. In Lewkowicz, A.G. \& Allard, M., eds. Proceedings of the Seventh International Conference on Permafrost. Yellowknife, Canada. Quebec: Centre d'études nordiques, Université Laval, 121-126.

Chown, S.L., Huiskes, A.H.L., Gremmen, N.J.M., Lee, J.E., Terauds, A., Crosbie, K., et al. 2012. Continent-wide risk assessment for the establishment of nonindigenous species in Antarctica. Proceedings of the National Academy of Sciences of the United States of America, 109, 4938-4943.

Claridge, G.G.C., Campbell, I.B. \& Balks, M.R. 1999. Movement of salts in Antarctic soils: experiments using lithium chloride. Permafrost and Periglacial Processes, 10, 223-233.

Convey, P. 2010. Terrestrial biodiversity in Antarctica - recent advances and future challenges. Polar Science, 4, 135-147.

Convey, P., Coulson, S.J., Worland, M.R. \& SJöblom, A. 2018. The importance of understanding annual and shorter-term temperature patterns and variation in the surface levels of polar soils for terrestrial biota. Polar Biology, 41, 1587-1605.

Convey, P., Hopkins, D.W., Roberts, S.J. \& Tyler, A.N. 2011. Global southern limit of flowering plants and moss peat accumulation. Polar Research, 30, 8929.

Convey, P., Chown, S.L., Clarke, A., Barnes, D.K., Bokhorst, S., Cummings, V., et al. 2014. The spatial structure of Antarctic biodiversity. Ecological Monographs, 84, 203-244.

Cowan, D.A., Chown, S.L., Convey, P., Tuffin, M., Hughes, K., PoINTING, S. \& VINCENT, W.F. 2011. Non-indigenous microorganisms in the Antarctic: assessing the risks. Trends in Microbiology, 19, 540-548.

Duffy, G.A., Coetzee, B.W., Latombe, G., Akerman, A.H., McGeoch, M.A. \& Chown, S.L. 2017. Barriers to globally invasive species are weakening across the Antarctic. Diversity and Distributions, 23, 982-996.

Goldsworthy, P., Canning, E. \& Riddle, M. 2003. Soil and water contamination in the Larsemann Hills, East Antarctica. Polar Record, 39, 319-337.

Grosse, G., Romanovsky, V., Jorgenson, T., Anthony, K.W., Brown, J. \& Overduin, P.P. 2011. Vulnerability and feedbacks of permafrost to climate change. Eos, Transactions American Geophysical Union, 92, $73-74$.

Hodgson, D.A., Convey, P., Verleyen, E., Vyverman, W., MCInNES, S.J., SANDS, C.J., et al. 2010. The limnology and biology of the Dufek Massif, Transantarctic Mountains 82 South. Polar Science, 4, 197-214

Houghton, M., McQuillan, P.B., Bergstrom, D.M., Frost, L., van den Hoff, J. \& SHaw, J. 2014. Pathways of alien invertebrate transfer to the Antarctic region. Polar Biology, 39, 23-33.

Huiskes, A., Convey, P. \& Bergstrom, D. 2006. Trends in Antarctic terrestrial and limnetic ecosystems: Antarctica as a global indicator. In Bergstrom, D.M., Convey, P. \& Huiskes, A.H.L., eds. Trends in Antarctic terrestrial and limnetic ecosystems. Berlin: Springer, 1-13.

JABOUR, J. 2009. National Antarctic programs and their impact on the environment. In Kerry, K.R. \& Riddle, M., eds. Health of Antarctic wildlife: a challenge for science and policy. Berlin: Springer, 211-229.

Kennicutt II, M.C., Klein, A., Montagna, P., Sweet, S., Wade, T., PAlmer, T., et al. 2010. Temporal and spatial patterns of anthropogenic disturbance at McMurdo Station, Antarctica. Environmental Research Letters, 5, 034010.

Kiernan, K. \& MCCONnEll, A. 2001a. Impacts of geoscience research on the physical environment of the Vestfold Hills, Antarctica. Australian Journal of Earth Sciences, 48, 767-776.

Kiernan, K. \& McConnell, A. 2001b. Land surface rehabilitation research in Antarctica. Proceedings - Linnean Society of New South Wales, 123, 101-118.
Klein, A.G., Sweet, S.T., Wade, T.L., Sericano, J.L. \& Kennicutt, M.C. 2012. Spatial patterns of total petroleum hydrocarbons in the terrestrial environment at McMurdo Station, Antarctica. Antarctic Science, 24, 450-466.

Klein, A.G., Kennicutt, M., Wolff, G.A., Sweet, S.T., Gielstra, D.A. \& Bloxom, T. 2004. Disruption of sand-wedge polygons at McMurdo Station, Antarctica: an indication of physical disturbance. In 61st Eastern Snow Conference, 159-172.

Lee, J.R., Raymond, B., Bracegirdle, T.J., Chades, I., Fuller, R.A., Shaw, J.D. \& Terauds, A. 2017. Climate change drives expansion of Antarctic ice-free habitat. Nature, 547, 49-54.

Molina-Montenegro, M.A., Carrasco-Urra, F., AcuñaRodríguez, I., Oses, R., Torres-Díaz, C. \& Chwedorzewska, K.J. 2014. Assessing the importance of human activities for the establishment of the invasive Poa annua in Antarctica. Polar Research, 33, 21425.

Morgan, F., Leathwick, J., Price, R., Keys, H. \& Zealand, A.N. 2005. Environmental domains analysis for the Antarctic continent. Landcare Research New Zealand, ATCM XXVIII/CEPVIII Information Paper, 2, 57.

Newman, J., Poirot, C., Roper-Gee, R., Leihy, R.I. \& Chown, S.L. 2018. A decade of invertebrate colonization pressure on Scott Base in the Ross Sea region. Biological Invasions, 20, 2623-2633.

O'NeILl, T.A. 2013. Soil physical impacts and recovery rates following human-induced disturbances in the Ross Sea Region of Antarctica. $\mathrm{PhD}$ thesis, University of Waikato, $369 \mathrm{pp}$.

O'NeILL, T.A. 2017. Protection of Antarctic soil environments: a review of the current issues and future challenges for the Environmental Protocol. Environmental Science \& Policy, 76, 153-164.

O'Neill, T., Aislabie, J. \& Balks, M. 2015a. Human impacts on soils. In Bockнeim, J.G., ed. The soils of Antarctica. Berlin: Springer, 281303.

O'Neill, T.A., Balks, M.R. \& López-Martínez, J. 2013. Visual recovery of desert pavement surfaces following impacts from vehicle and foot traffic in the Ross Sea region of Antarctica. Antarctic Science, 25, $514-530$.

O'Neill, T., Balks, M. \& López-Martínez, J. 2015b. Ross Island recreational walking tracks: relationships between soil physiochemical properties and track usage. Polar Record, 51, 444-455.

O'Neill, T.A., Balks, M.R., Lopez-Martinez, J. \& McWhirter, J.L. 2012. A method for assessing the physical recovery of Antarctic desert pavements following human-induced disturbances: a case study in the Ross Sea region of Antarctica. Journal of Environmental Management, 112, 415-428.

Olech, M. 1996. Human impact on terrestrial ecosystems in West Antarctica. NIPR Symposium on Polar Biology, Proceedings, 9, 299-306.

Olech, M. \& Chwedorzewska, K.J. 2011. The first appearance and establishment of an alien vascular plant in natural habitats on the forefield of a retreating glacier in Antarctica. Antarctic Science, 23, $153-154$

Pertierra, L.R., Lara, F., Benayas, J., Lewis-Smith, R.I. \& Hughes, K.A. 2017. Conflicting science requirements impact on rare moss conservation measures. Antarctic Science, 30, 13-21.

Pertierra, L.R., Lara, F., Tejedo, P., Quesada, A. \& Benayas, J. 2013. Rapid denudation processes in cryptogamic communities from Maritime Antarctica subjected to human trampling. Antarctic Science, 25, 318-328.

Robinson, S.A., King, D.H., Bramley-Alves, J., Waterman, M.J., Ashcroft, M.B., Wasley, J., et al. 2018. Rapid change in East Antarctic terrestrial vegetation in response to regional drying. Nature Climate Change, 8, 879-884.

Sheppard, D., Deely, J. \& Edgerley, W. 1997. Heavy metal content of meltwaters from the Ross Dependency, Antarctica. New Zealand Journal of Marine and Freshwater Research, 31, 313-325. 
Soll Survey Staff. 2014. Keys to soil taxonomy. Washington, DC: United States Department of Agriculture, Natural Resources Conservation Service, $360 \mathrm{pp}$.

Tejedo, P., Justel, A., Rico, E., Benayas, J. \& Quesada, A. 2005. Measuring impacts on soils by human activity in an Antarctic Special Protected Area. Terra Antarctica Reports, 12, 57-62.

Tejedo, P., Justel, A., Benayas, J., Rico, E., Convey, P. \& Quesada, A. 2009. Soil trampling in an Antarctic Specially Protected Area: tools to assess levels of human impact. Antarctic Science, 21, 229-236.

Tejedo, P., Benayas, J., Cajiao, D., Albertos, B., Lara, F., Pertierra, L.R., et al. 2016. Assessing environmental conditions of Antarctic footpaths to support management decisions. Journal of Environmental Management, 177, 320-330.
Terauds, A. \& LeE, J.R. 2016. Antarctic biogeography revisited: updating the Antarctic Conservation Biogeographic Regions Diversity and Distributions, 22, 836-840.

Tin, T., Fleming, Z.L., Hughes, K.A., Ainley, D.G., Convey, P., Moreno, C.A., et al. 2009. Impacts of local human activities on the Antarctic environment. Antarctic Science, 21, 3-33.

Wall, D.H. \& Virginia, R.A. 1999. Controls on soil biodiversity: insights from extreme environments. Applied Soil Ecology, 13, 137-150.

Wilson, K.-J., TAYLOR, R.H. \& BARTON, K.J. 1990. The impact of man on Adélie penguins at Cape Hallett, Antarctica. Berlin: Springer, 183-190. 